\section{References}

1. Chauvaud S, Serraf A, Milhaileanu S, Soyer R, Blondeau P, Dubost C, et al. Ventricular septal defect associated with aortic valve incompetence: results of two surgical managements. Ann Thorac Surg. 1990; 49:875-80.

2. Trusler GA, Moes CAF, Kidd BSL. Repair of ventricular septal defect with aortic insufficiency. J Thorac Cardiovasc Surg. 1973;66:394-403.
3. Spencer FC, Doyle EF, Danilowicz DA, Bahnson HT, Weldon CS. Long-term evaluation of aortic valvuloplasty for aortic insufficiency and ventricular septal defect. J Thorac Cardiovasc Surg. 1973;65:15-31.

4. Kalangos A, Beghetti M, Murith N, Faidutti B. Leaflet's free edge suspension for correction of aortic insufficiency associated with ventricular septal defect. Ann Thorac Surg. 1998;65:566-8.

5. David TE, Armstrong S, Ivanov J, Feindel CM, Omran A, Webb G. Results of aortic valve-sparing operations. J Thorac Cardiovasc Surg. 2001;122:39-46.

\title{
Half-turned truncal switch operation for complete transposition of the great arteries with ventricular septal defect and pulmonary stenosis
}

\author{
Masaaki Yamagishi, MD, Keisuke Shuntoh, MD, Tsutomu Matsushita, MD, Katsuji Fujiwara, MD, Takeshi Shinkawa, MD, \\ Takako Miyazaki, MD, and Nobuo Kitamura, MD, Kyoto, Japan
}

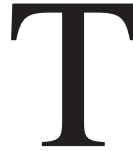

he Rastelli ${ }^{1}$ or Lecompte operations (réparation à l'étage ventriculaire) $)^{2}$ are commonly used for complete transposition of the great arteries (TGA) with anterior aorta, ventricular septal defect (VSD), and pulmonary stenosis (PS) or a double-outlet right ventricle with anterior aorta and a left posterior overriding pulmonary artery (PA; ie, false Taussig-Bing heart ${ }^{3}$ ) with PS. However, a warped left ventricular outflow tract through a space-occupied intraventricular tunnel and a contrived right ventricular outflow tract are inevitable in these conventional operations. We developed an alternative surgical option to ensure straight and nonobstructive aortic and pulmonary ventricular outflow tracts by using an autologous half-turned truncal block that involves both semilunar valves.

\section{Clinical Summary}

A girl weighing $7100 \mathrm{~g}$ was referred to our hospital for surgical repair. By means of echocardiography and angiocardiography, the cardiac anatomy was diagnosed as TGA with anterior aorta, VSD, and both valvular and subvalvular PS. A large muscular outlet VSD was located at a juxtapulmonary position. The infundibular septum was deviated posteriorly, and the posterior PA was overriding the interventricular septum. The pulmonary valve was bicuspid, and the pressure gradient between the left ventricle and the PA was $65 \mathrm{~mm} \mathrm{Hg}$.

From the Division of Pediatric Cardiovascular Surgery, Children's Research Hospital, Kyoto Prefectural University of Medicine, Kyoto, Japan.

Received for publication July 21, 2002; accepted for publication Aug 16, 2002.

Address for reprints: Masaaki Yamagishi, MD, Division of Pediatric Cardiovascular Surgery, Children's Research Hospital, Kyoto Prefectural University of Medicine, Kawaramachi, Hirokoji, Kamikyo-ku, Kyoto, 6028566 Japan (E-mail: myama@koto.kpu-m.ac.jp).

J Thorac Cardiovasc Surg 2003;125:966-8

Copyright $\odot 2003$ by The American Association for Thoracic Surgery $0022-5223 / 2003 \$ 30.00+0$

doi: $10.1067 / \mathrm{mtc} .2003 .33$
At 1 year of age, surgical repair was performed through a median sternotomy. The ascending aorta was located anteriorly, and the main pulmonary artery (MPA) was located posteriorly. The coronary arterial pattern was Yacoub type A. A large right ventricular branch artery was detected at the right ventricular outflow tract. An arterial cannula was inserted into the ascending aorta, and venous return cannulas were directly inserted into the superior and inferior venae cavae. After institution of moderate hypothermic cardiopulmonary bypass and subsequent chemical cardiac arrest, the ascending aorta was transected $10 \mathrm{~mm}$ above the coronary orifices (Figure 1, $A$ ). The incised line of the truncal root was designed around both semilunar valve annuli (Figure 1, B, dotted line). Also, the incised line on the PA was designed obliquely from the posterior aspect of the proximal site to the anterior aspect of the bifurcation (Figure 1, B, dotted line). The PA was incised obliquely along the designed line so as to retain the anterior wall with the proximal PA stump. Both right and left coronary arterial buttons were resected with a U-shaped incision (Figure 1, $C)$. The right ventricular outflow tract was incised along the aortic annulus (Figure 1,D). The infundibular septum was incised at both the right and left margins (Figure 1, D, dotted line). The incision was extended along the pulmonary annulus. With care taken to avoid mitral valve injury, the midline of the fibrous continuity between the pulmonary valve and the mitral valve was incised. By means of this maneuver, a truncal block, which included the entire aortic and pulmonary valves, was resected. The resected truncal block was half turned horizontally (Figure 1,E). The anterior wall of the anteriorly translocated PA was incised longitudinally through the anterior pulmonary commissure. The posteriorly translocated aortic valve was anastomosed to the left ventricular outflow tract with a continuous 5-0 polypropylene suture (Pronova; Ethicon, Inc, Somerville, NJ; Figure 1, F). A nontwisted expanded polytetrafluoroethylene (ePTFE) patch (W. L. Gore \& Associates, Inc, Flagstaff, Ariz) was anastomosed along the VSD edge with pledget-reinforced mattress sutures. The superior margin of the ePTFE patch was anastomosed to the prominence of the infundibular septum. A straight left ventricular outflow tract was then created. The coronary cuffs were anastomosed to the confronted 

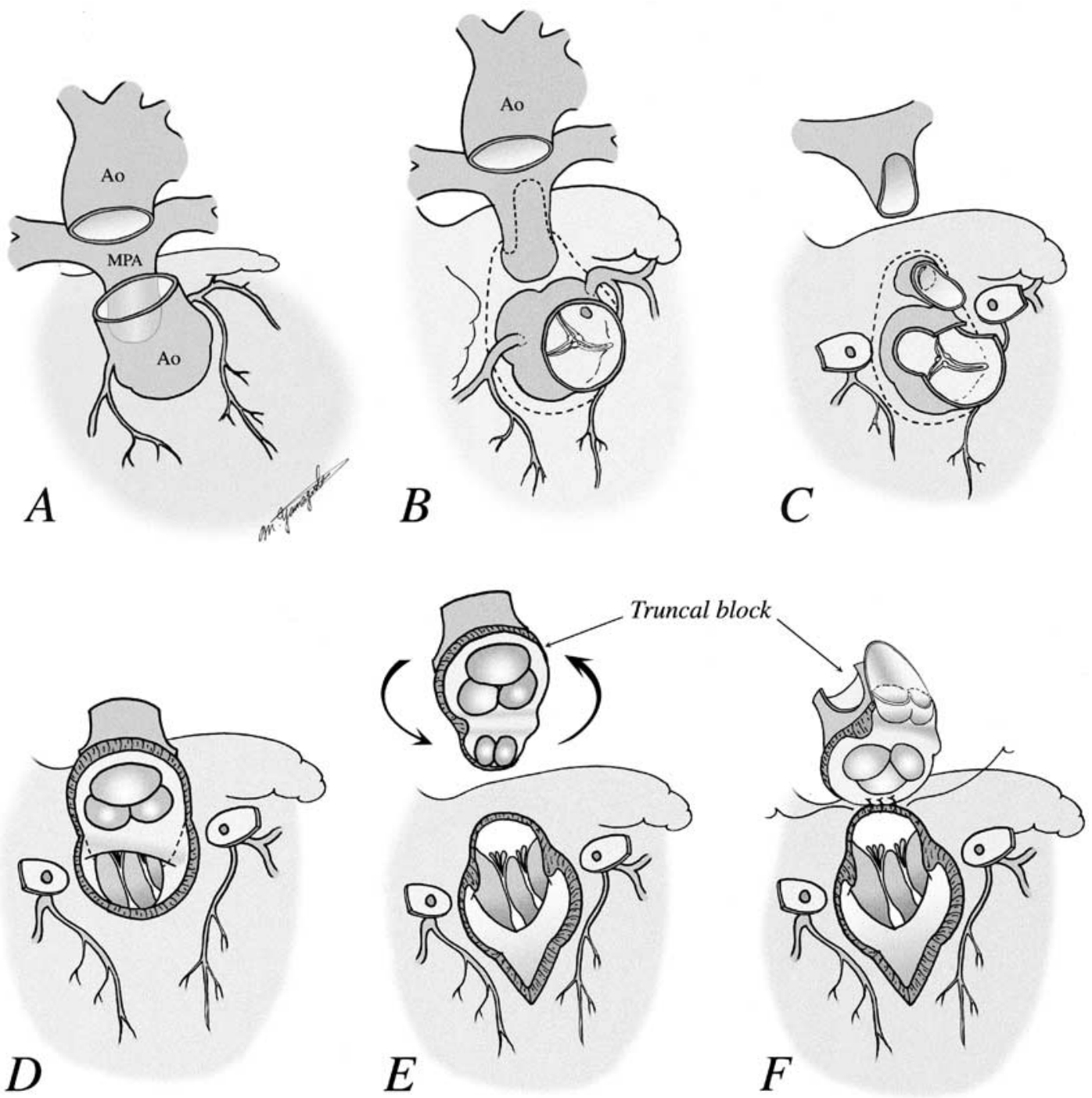

Figure 1. A, The aorta (Ao) was located anteriorly, and the MPA was located posteriorly. The aorta was transected $10 \mathrm{~mm}$ above the coronary orifices. B, Anterosuperior view of the truncal root. The dotted line indicates the incised line. The supposed incised line on the MPA runs obliquely from the posterior wall of the pulmonary annulus to the anterior wall of the pulmonary bifurcation. C, The MPA was incised obliquely so as to keep the anterior wall to the proximal side. Both coronary arterial buttons were resected. D, Along the aortic annulus, the anterior wall of the right ventricle was incised. The dotted line indicates the incised line on the infundibular septum. E, The midline of the fibrous continuity between the pulmonary valve and the mitral valve was incised. The truncal block involving both semilunar valves was separated from the ventricular outflow tract. The resected truncal block was half turned. F, The half-turned truncal block was anastomosed to the ventricular outflow tract. First, the posteriorly translocated aortic annulus was anastomosed to the left ventricular outflow orifice. The up-front pulmonary commissure was cut through.

aortic wall defects with continuous 7-0 polydioxanone sutures (Ethicon; Figure 1, $G$ ). After the pulmonary bifurcation was translocated anteriorly, the ascending aorta was reconstructed by means of end-to-end anastomosis. The posterior wall of the proximal pulmonary stump, which was the anterior wall before the half-turn maneuver, was anastomosed to the posterior wall of the pulmonary bifurcation (Figure 1, $H$ ). Because the PA was transected obliquely, both walls were within easy reach. The anterior wall of the neo-right ventricular outflow tract was covered with an autologous pericardial patch equipped with a monocuspid fan-shaped ePTFE valve (Figure 1,I). The tricuspid pulmonary valve was reconstructed together with native pulmonary cusps.

There was no conduction disturbance. Postoperative Doppler echocardiography showed laminar flow through a straight left ventricular outflow tract and a nonobstructed right ventricular outflow tract. 


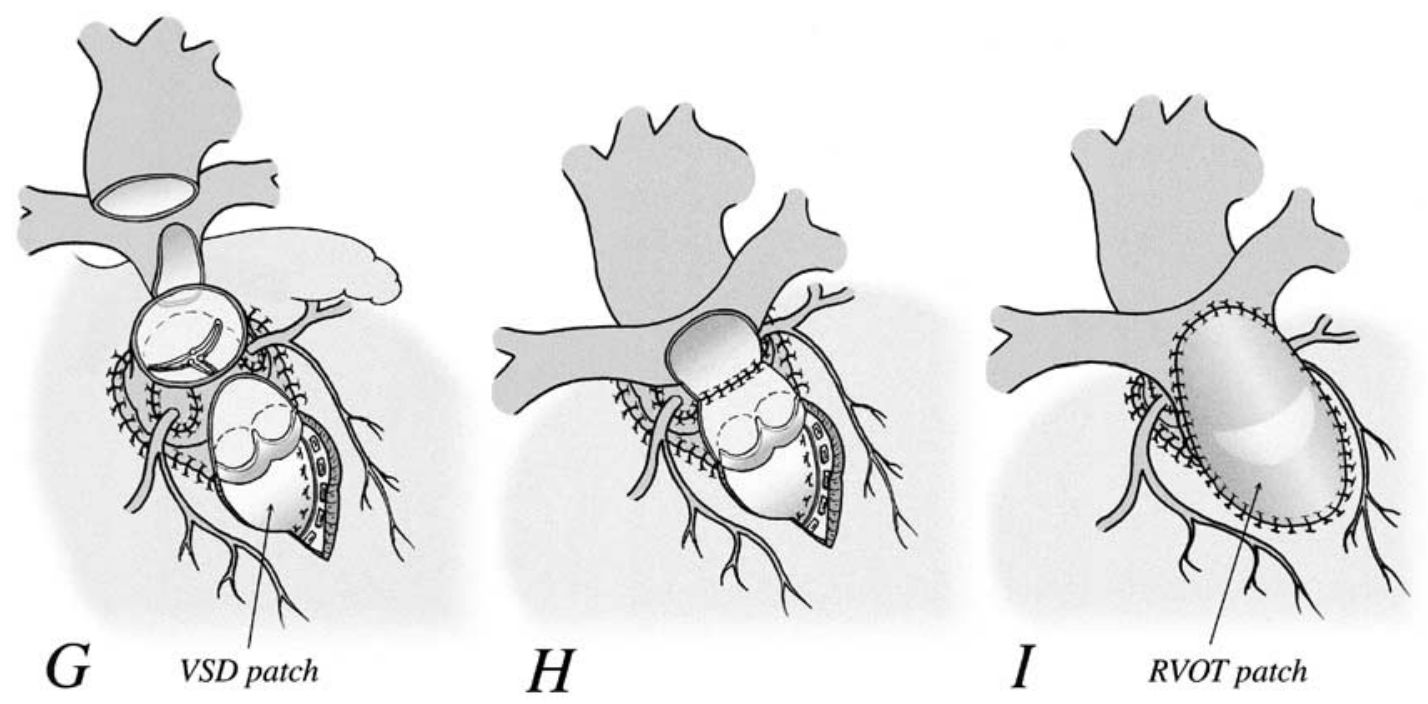

Figure 1. Cont'd. G, After anastomosis of the aortic annulus, both coronary buttons were anastomosed to the corresponding defects of the aortic wall. The VSD was closed with an ePTFE patch (VSD patch). The superior margin of the patch was anastomosed to the prominence of the infundibular septum. $H$, After the pulmonary bifurcation was translocated anteriorly, the ascending aorta was reconstructed by means of end-to-end anastomosis. Continuity of the posterior pulmonary wall was reconstructed by means of direct anastomosis with each remnant wall. I, The right ventricular outflow tract was covered with an autologous pericardial patch (RVOT patch) equipped with a monocuspid ePTFE valve.

\section{Discussion}

An inevitable late complication after the Rastelli or the Lecompte operation is the development of outflow obstruction of the left or right ventricle or of both ventricles. ${ }^{4-6}$ The VSD diminution caused by the postoperative geometric change of the left ventricle 5 and a narrowing of the intraventricular tunnel induces left ventricular outflow tract obstruction. The extracardiac prosthetic conduit in the Rastelli operation and a stretched MPA, which is translocated anteriorly to the huge aorta in the Lecompte operation, are primary causes of right ventricular outflow tract obstruction. As an alternative, the Nikaidoh operation ${ }^{7}$ is a novel technique to overcome the faults of the Rastelli and Lecompte operations; however, it has serious drawbacks concerning coronary insufficiency and subsequent myocardial damage.

The advantages of our technique are as follows. Late left ventricular outflow tract obstruction is entirely avoided with our technique because a wide and straight left ventricular outflow tract is provided by means of posterior translocation of the ascending aorta and because the systemic bloodstream is not passed through either the VSD or the intraventricular tunnel. Oblique transection of the MPA and the truncal half-turn maneuver provide sufficient length of the autologous pulmonary posterior wall for direct anastomosis by itself. Overstretching of the MPA is avoided by means of posterior translocation of the ascending aorta to make room for the MPA on the right ventricular outflow tract. The preserved autologous pulmonary valve is effective in preventing pulmonary regurgitation. The risk of late right ventricular outflow tract obstruction will be significantly reduced by elimination of the extracardiac conduit and by the nonstretched MPA. The growth potential of the MPA is also preserved.
Our technique is a useful alternative to the Rastelli or Lecompte operations for TGA with VSD and PS or for the false Taussig-Bing anomaly with PS. However, the use of this technique would be contraindicated in patients with complex coronary patterns, such as the right coronary artery crossing the right ventricular outflow tract.

\section{References}

1. Rastelli GC, Wallace RB, Ongley PA. Complete repair of transposition of the great arteries with pulmonary stenosis: a review and report of a case corrected by using a new surgical technique. Circulation. 1969;39:83-95.

2. Lecompte Y, Neveux JY, Leca F, Zannini L, Tu TV, Duboys Y, et al. Reconstruction of the pulmonary outflow tract without prosthetic conduit. J Thorac Cardiovasc Surg. 1982;84:727-33.

3. Kurosawa H, Van Mierop LH. Surgical anatomy of the infundibular septum in transposition of the great arteries with ventricular septal defect. J Thorac Cardiovasc Surg. 1986;91:123-32.

4. Vouhé PR, Tamisier D, Leca F, Ouaknine R, Vernant F, Neveux JY. Transposition of the great arteries, ventricular septal defect, and pulmonary outflow tract obstruction: Rastelli or Lecompte procedure? J Thorac Cardiovasc Surg. 1992;103:428-36.

5. Rychik J, Jacobs ML, Norwood WI. Early changes in ventricular geometry and ventricular septal defect size following Rastelli operation or intraventricular baffle repair for conotruncal anomaly: a cause for development of subaortic stenosis. Circulation. 1994;90(Suppl): II-13-9.

6. Kreutzer C, De Vive J, Oppido G, Kreutzer J, Gauvreau K, Freed M, et al. Twenty-five-year experience with Rastelli repair for transposition of the great arteries. J Thorac Cardiovasc Surg. 2000;120:211-23.

7. Nikaidoh $\mathrm{H}$. Aortic translocation and biventricular outflow tract reconstruction: a new surgical repair for transposition of the great arteries associated with ventricular septal defect and pulmonary stenosis. J Thorac Cardiovasc Surg. 1984;88:365-72. 